\title{
Interference of natural vibrations in four-point bending test on beams with asphalt composite made with calcined clay aggregate
}

\author{
A. C. L. da Silva ${ }^{1 *}$, C. L. da Silva ${ }^{I}$, A. K. C.Monteiro ${ }^{I}$, C. A. Frota ${ }^{I}$ \\ ${ }^{1}$ Universidade Federal do Amazonas, Faculdade de Tecnologia, Grupo de Geotecnia, Av. Gen. Rodrigo Octávio \\ Jordão Ramos 3000, 69077-000, Manaus, AM, Brazil
}

\begin{abstract}
Relevant mechanical parameters of asphalt composites, such as the dynamic modulus and phase angle, are obtained by means of four-point bending tests. It is a dynamic test based on the application of sinusoidal load pulses and sinusoidal displacement response. A sinusoidal response can be difficult to record due to different issues, such as noise during an experiment. In strain-controlled tests with the application of a low-load amplitude with asphalt mixtures at high temperatures composed with calcined clay, which is the case of the test carried out in this study, a relationship was observed between the apparent noise recorded and the frequencies of the beam's natural vibration. This outcome led to the conclusion that these imperfections are not a result of failures in the procedure, but of the natural behavior of the beam. This conclusion can assist in the filtering of information to obtain better results.
\end{abstract}

Keywords: dynamic modulus, asphalt mixtures, four-point bending test, natural vibration.

\section{INTRODUCTION}

In Geotechnical Engineering, pavements are structures designed with the objective of guaranteeing a comfortable and safe circulation of vehicles and aircrafts. They consist of a multilayer system laid on natural soil (foundation or subgrade), subjected to efforts arising from numerous combinations of loads from vehicle traffic and various environmental conditions [1]. In the case of so-called flexible pavements, they have an asphalt coating, usually asphalt concrete (AC), which is composed of coarse aggregates, such as crushed stones. However, in conditions where there is an insufficiency of superficial stone, these pavements can be composed of a rolled pebble from riverbeds, a solution that results in a lower technical quality of this upper layer and causes serious environmental impacts, stimulating the study of new materials. An alternative for this situation is to use sintered calcined clay aggregate (SCCA) as a coarse aggregate [2-12]. Specifically, regarding asphalt binder, its viscoelastic characteristics must also be taken into consideration in this composition, as its consistency and strains are a function of the variation in temperature and time of load application. At high temperatures, the binder is a viscous fluid while at low temperatures the viscosity decreases, and it becomes an elastic solid for loads applied in short periods of time. Therefore, this characteristic must match the environment temperature, such as the high temperatures found in equatorial climate zones, where the Brazilian Amazon is located.

Moreover, it is important to consider the mechanical parameters of asphalt concrete (AC), in special its stiffness

*cleiton.acls@hotmail.com

Dhttps://orcid.org/0000-0001-7343-350X
[13]. Simply put, stiffness is a property defined as the slope of stress vs. strain curve. It is a characteristic of the material and does not depend on the device used for measurement, nor on the size or shape of the sample. When determined through a dynamic test, by applying sinusoidal load pulses with the monitoring of sinusoidal displacements, it is referred to as a stiffness modulus or complex modulus [14]. However, it is often difficult to obtain a sinusoidal response in this type of experiment, due to several factors, in special because of the noise present throughout the experiment. In this context, the fast Fourier transform is a filtering method that can be used to process stress and strain signals. Likewise, several regression techniques have been employed to smooth data [15]. It should be noted, however, that there is a lack of technical-scientific works in the literature addressing such methodologies in dynamic experiments with asphalt formulations [16-18]. That being said, the present research explores the cause of apparent noise in the results of a fourpoint bending test performed on asphalt concrete specimens, especially at high temperatures. This paper also investigates its relationship with the natural vibrations of these samples (beams) to enable better filtering and correction of the results obtained.

\section{MATERIALS AND METHODS}

Considering the scarcity of rock raw materials from superficial layers and the thick clay layer present in the geotechnical soil profile of a great part of the state of Amazonas, sintered calcined clay aggregate (SCCA) was chosen as a coarse aggregate to replace the crushed stone. This material was also selected due to the promising results obtained from it. The physical characterization of this alternative aggregate resulted in the following values: $2.571 \mathrm{~g} / \mathrm{cm}^{3}$ for bulk specific gravity (Gsa) and $1.855 \mathrm{~g} / \mathrm{cm}^{3}$ for apparent specific gravity 
(Gsb); in addition, a satisfactory adhesion and a high value for absorption of $15 \%$, in relation to stone aggregates. Sand (fine aggregate) sold in the region was also included in the asphalt mixture, showing values of $2.692 \mathrm{~g} / \mathrm{cm}^{3}$ for Gsa and $2.632 \mathrm{~g} / \mathrm{cm}^{3}$ for Gsb. As a filler, the common Portland CP IIZ-32 cement used in regional civil works was incorporated into the asphalt mixture. Finally, the composition included petroleum asphalt cement, classified as AC 50-70 according to requirements of the Brazilian National Agency for Petroleum, Natural Gas and Biofuels. This cement originated from the refining of Brazilian oils at Campo Fazenda Alegre (state of Espírito Santo, Brazil) and Ceará-Mar (state of Ceará, Brazil). These materials followed the standards of the Association of State Highway and Officials, the American Society for Testing and Materials (ASTM), and the National Department of Transport Infrastructure (DNIT) of Brazil [19].

The sintered calcined clay aggregate (SCCA) was fabricated by the GEOTEC research group of the Federal University of Amazonas, from a soil extracted in the Petroleum Province of Urucu, located $650 \mathrm{~km}$ from the city of Manaus/AM-Brazil. The production process consisted of molding, calcination, and subsequent crushing of solid bricks (60x110x200 mm), with two $\varnothing 16 \mathrm{~mm}$ central holes. They were made specifically for this purpose, using the facilities of traditional pottery from the Pottery Pole surrounding the city of Manaus/AM. Subsequently, in order to restrict the maximum diameter due to the limitations of the beam mold, the SCCA coarse aggregate was fractionated, thus resulting in a new batch of the material. Fig. 1 illustrates the granulometric distributions of the SCCA, its fractional portion, and the sand used in the asphalt composite. Under the chemical aspect, the calcined clay aggregate consisted mainly of $55.0 \%$ of silicon dioxide $\left(\mathrm{SiO}_{2}\right)$ and $37.1 \%$ of aluminum oxide $\left(\mathrm{Al}_{2} \mathrm{O}_{3}\right)$, according to the X-ray fluorescence (XRF) spectroscopy. With regard to the mineralogical composition, the X-ray diffraction (XRD) results indicated a predominance of quartz, and characteristic peaks of kaolinite and hematite (Fig. 2).

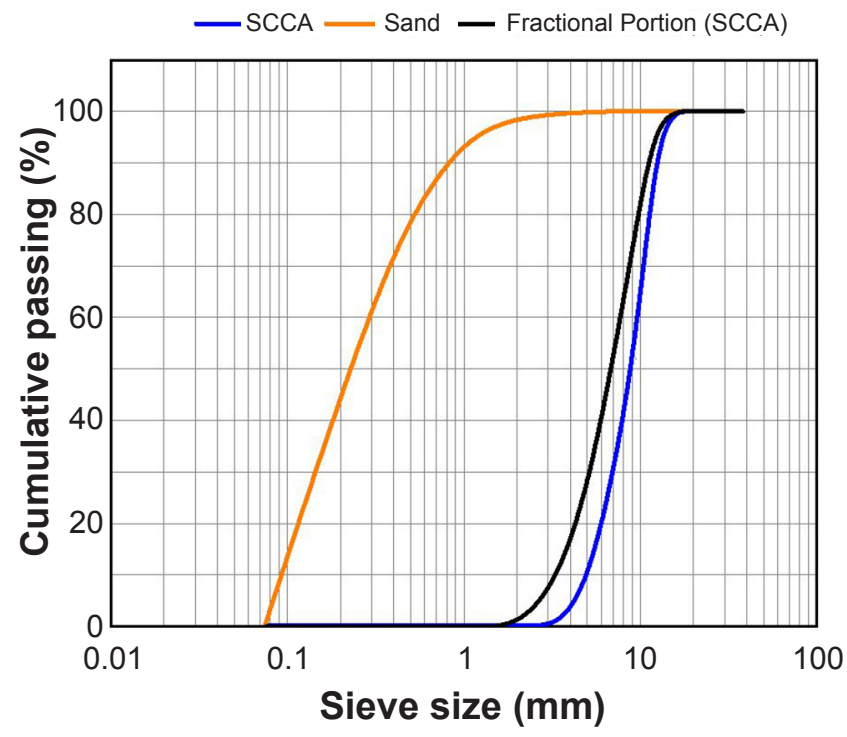

Figure 1: Particle size distribution curves of aggregates.

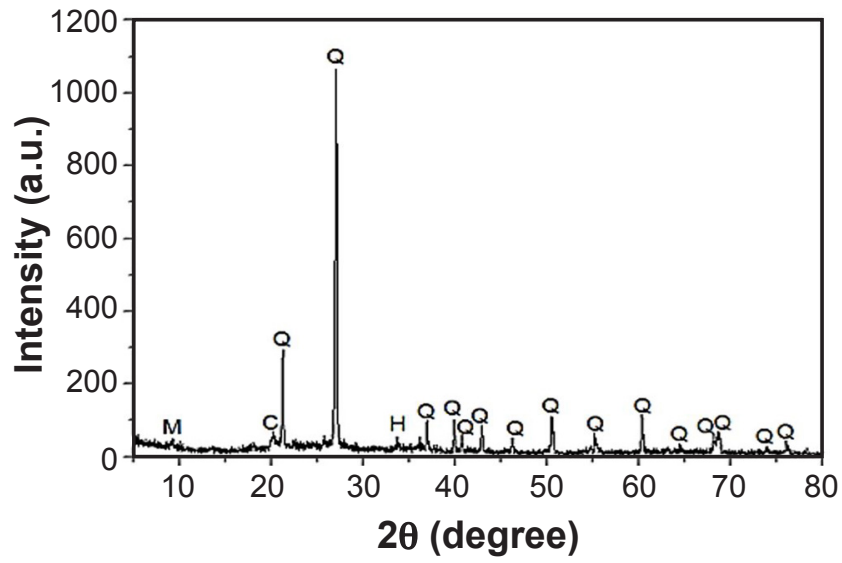

Figure 2: XRD pattern of SCCA. C: kaolinite; H: hematite; M: muscovite; Q: quartz.

From the characterization of the aforementioned materials, the final dosage was determined, in accordance with the set of criteria of the Superpave method, and in particular for a void volume ( $\mathrm{Vv})$ of $4 \%$. The result indicated $62 \%$ of SCCA, $34 \%$ of sand, $4 \%$ of Portland cement, and $10.9 \%$ of AC 50/70. It is interesting to highlight that this high value of the binder content was due to the high absorption value of $15 \%$ for sintered calcined clay aggregate (SCCA) as compared to stone aggregates. Based on this composition, the prismatic specimens (beams) tested at four-point bending were compacted using a superpave gyratory compactor (SGC) [19].

Four-point bending test: the four-point bending test consisted of taking a prismatic beam with four supports and applying a load on the two internal points located at onethird from the ends. The other two supports, which were of the articulated type, were located at the ends and rotated without allowing a displacement towards the applied load. This configuration enabled the central span of the beam to be subjected to pure bending, which allowed it to get close to the premises for the development of the beam's general equations [20-25]. Thus, the load caused a constant bending moment along with the central third, as well as a state of uniform stress in that section of the beam. Moreover, there were no shear stresses in that region. This approximated the experimental arrangement to the general hypotheses adopted for calculating deformations on a beam, which consider the occurrence of pure bending. Likewise, the deformations on the center of the beam were free of effects resulting from stress concentration points since the loads were concentrated in the middle thirds. In summary, this experimental configuration consisting of four points reduced the uncertainties and the propagation of errors, as well as the dispersion of results. Based on the bending formula and the beam elastic line equation, and taking this loading in particular, the equations that provide both the tension stress on the external strains and the deflection were obtained. Thus, the stress, stiffness modulus, and the specific strain at the center of the beam span were calculated through Eqs. A to $\mathrm{C}$, respectively [19]: 


$$
\begin{aligned}
& \sigma=\frac{P \cdot l}{b \cdot h^{2}} \\
& E_{S}=\frac{23 \cdot P \cdot l^{3}}{108 \cdot b \cdot h^{3} \cdot \Delta} \\
& \varepsilon_{\tau}=\frac{\sigma}{E_{S}}=\frac{108 \cdot h \cdot \Delta}{23 \cdot 1^{2}}
\end{aligned}
$$

where, $\sigma$ is the normal stress, $\mathrm{E}_{\mathrm{s}}$ the elastic modulus, $\Delta$ the beam deflection, $\mathrm{P}$ the load, 1 the length, $\mathrm{b}$ the beam width (base), h the beam height, and $\varepsilon_{\mathrm{t}}$ the specific strain.

The test for calculating the stiffness modulus, specified by standard EN 12697-26, was based on the transmission of a sinusoidal load on the prismatic specimen (beam), determining the applied load and the corresponding deflection. It should be noted that the tests were carried out at temperatures starting at $25{ }^{\circ} \mathrm{C}$, gradually increasing by $5{ }^{\circ} \mathrm{C}$ until reaching $55^{\circ} \mathrm{C}$ to better represent the environmental conditions of tropical regions. Regarding the load application frequencies, a series of 1, 3, 10, and 20 $\mathrm{Hz}$ was used to simulate the actions generated by vehicle traffic at the base of the pavement asphalt layer. Note that the repetition of the first frequency aimed to verify whether the sample (beam) was damaged during the experiment. If the difference in the stiffness modulus values between the first and last measurement for the same temperature was greater than $3 \%$, the specimen was damaged. Specific to the loading mode, a controlled strain was used, with a maximum strain range of $50 \mu \mathrm{m} / \mathrm{m}$; a value that, according to the standard, does not cause damage to the sample (beam). As previously mentioned, it was necessary to preserve the specimens for the sequence of tests.

Sample preparation: the prismatic beams were prepared by compacting the asphalt mass in a metallic mold with sufficient rigidity to allow its densification without the occurrence of deformation. Therefore, the dimensions within the tolerance limits of the European standard EN 12697-26 were safeguarded. This mold was also manufactured to allow its total dismantlement, that is, to facilitate the removal of the specimen. It consisted of a base, on which the side pieces were fixed, and a very rigid metallic upper part that fitted inside the mold, on which a load was applied for compaction according to parameters established in the dosage procedure. Furthermore, it should be noted that the mineral components were heated to a temperature that guaranteed the adequate viscosity of the binder in the mixture, in the proportions established by the dosage test, and in the exact quantities for molding the beams. These materials were mixed with the AC until they became completely homogenized; afterward, they were poured into the preheated mold at the same temperature, and the asphalt mixture became dense, reaching the desired height depending on the degree of compaction of the material. The beams with the characteristics presented in Table I were analyzed. Each one was subjected to all combinations of load application frequency and temperature variations mentioned.
Table I - Data of beams subjected to the test.

\begin{tabular}{ccccc}
\hline Beam & $\begin{array}{c}\text { Mass } \\
(\mathrm{g})\end{array}$ & $\begin{array}{c}\text { Height } \\
(\mathrm{mm})\end{array}$ & $\begin{array}{c}\text { Volume } \\
\left(\mathrm{cm}^{3}\right)\end{array}$ & $\begin{array}{c}\text { Density } \\
\left(\mathrm{g} / \mathrm{cm}^{3}\right)\end{array}$ \\
\hline V1 & 2443 & 51.3 & 1324 & 1.845 \\
V2 & 2461 & 51.9 & 1338 & 1.839 \\
V3 & 2449 & 51.5 & 1328 & 1.844 \\
V4 & 2465 & 51.7 & 1333 & 1.849 \\
V5 & 2454 & 51.8 & 1337 & 1.835 \\
\hline Note: all beams had a length of 400 mm and a base length of $64.5 \mathrm{~mm}$.
\end{tabular}

Equipment: in order to simulate the theoretical model according to the four-point bending test, it is necessary to have an equipment with support for a prismatic specimen (beam), with supports that restrict vertical displacement, but allow free rotation and horizontal displacement. Fig. 3 schematically represents the arrangement of the loads and ties of the supports of the device. This device consisted of a pneumatic system for the transmission of force to the two internal supports, transducers for data acquisition, and a control unit connected to a personal computer, which enabled the configuration and recording of the acquired data. Moreover, it had an environmental chamber capable of varying the temperature. This instrument was pertinent because the measurements must be very precise for the discretization of the effects of natural vibrations in the acquisition of data with a low load and high speed. The nominal capacity of such equipment was $\pm 4.5 \mathrm{kN}$. It had a digital data acquisition system with a resolution of 20-bit and was self-adjustable to the operation scale. For a better understanding of the equipment resolution, a resolution of 20 bit means that it can register $1 / 2^{20}$ equivalent parts of the amplitude, that is, $9000 \mathrm{~N} / 1048576=0.0085 \mathrm{~N}$. As for data acquisition, the device was equipped with several systems and resources that automatically adjusted to each test condition, aiming at greater efficiency. Overall, the software automatically adjusted the frequency of acquisition to avoid recording too much data, but in a sufficient quantity for perfect conformation of the load pulses and corresponding displacement. Consequently, for $1 \mathrm{~Hz}$ load pulses, data acquisition occurred every $0.004 \mathrm{~s}$ (250 points per second), and for $20 \mathrm{~Hz}$, every $0.0004 \mathrm{~s}$ (2500 points per second), which was equivalent to 125 points per cycle.

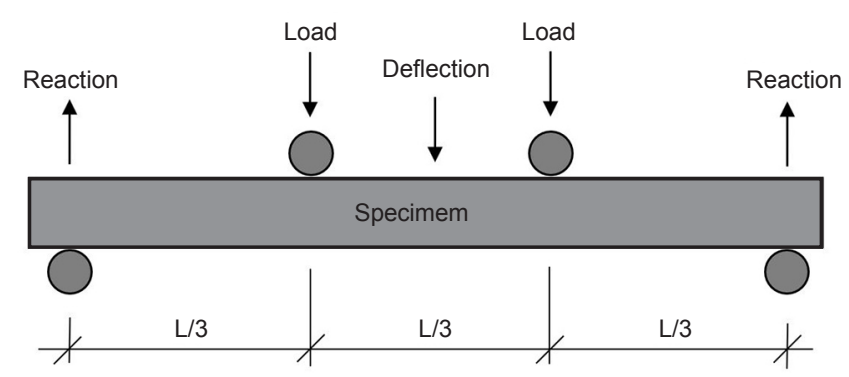

Figure 3: Loading and support ties scheme in the four-point bending machine. 
Beam vibrations: every body is subjected to natural or forced vibration. The various manifestations of vibrations can be beneficial to certain applications, such as with ultrasound instrumentation, and harmful to others, such as oscillating stresses in structural elements, which can produce damage due to fatigue. Vibrations are also undesirable during measurements with precision instruments, such as in the tests performed in this study, which is why it is important to understand them. A beam free of loading with both ends with restricted vertical movement, but with the possibility of rotating freely (bi-articulated beam), when experiencing a disturbance vibrates at a certain natural frequency. This frequency depends on the material and geometric parameters. Graff [26], who developed a study of the movement of waves in elastic solids, introduced the equation that describes the natural frequency of free vibrations in beams for different boundary conditions, with a particular example of a biarticulated beam according to:

$$
f_{n}=\frac{n^{2} \cdot \pi}{2.1^{2}} \sqrt{\frac{E . I}{\rho . A}} \quad(n=1,2,3 \ldots)
$$

where $f_{n}$ is the natural frequency, 1 is the length, $E$ is the elastic modulus, $\mathrm{Q}$ is the density, A is the cross-section area, and $\mathrm{n}$ represents the vibration mode of the beam. The simplest vibration mode is observed to occur when the entire beam bends upwards or downwards. Another possible route is when half of the beam bends upwards and the other half downwards, alternately, forming an internal knot that divides it into two parts. It can also occur with two intermediate nodes, dividing the beam into three equal parts and alternating curvatures. In Eq. D, the frequencies of natural vibration seem to be directly proportional to the square root of the elastic modulus. For the same specimen, Eq. E results in the relationship between two frequencies:

$$
\frac{\mathrm{fn}_{1}}{\mathrm{fn}_{2}}=\sqrt{\frac{\mathrm{E}_{1}}{\mathrm{E}_{2}}}
$$

Especially for asphalt concrete, the temperature greatly affects the stiffness modulus, which decreases with the increase in temperature. Thus, Eq. E indicates that for the same beam and vibration mode, the natural frequency decreases as the temperature increases. In combination with the beam's natural vibration, under dynamic loading conditions, a forced oscillation also occurs, which is the test oscillation. In this case, there is an overlap of effects, and the recordings of the beam's vertical displacements will suffer the effect resulting from the natural vibration with the forced displacement. In terms of amplitude, the result will be the sum of the amplitude forced by the external agent with that which originates in the beam's natural vibration. Thus, for comparatively large forced amplitudes in relation to the natural one, the resulting wave will be little influenced by the natural vibration and will be practically equal to that of the isolated forced movement. On the contrary, the resulting wave will be greatly influenced by the beam's natural vibration and may be confused with noise and impair result interpretations. Thus, it is important to identify and understand this natural vibration, which can be used to refine results.

\section{RESULTS AND DISCUSSION}

There are studies in the literature that address the concern regarding the accuracy of the results from four-point bending tests. Huurman and Pronk [27] demonstrate the benefits of calibration tests, which substantially decreased errors arising from the use of the equipment. Also noteworthy are studies that present results that do not fit perfectly with the expected model and are often interpreted as the result of noise resulting from the sensitivity of the equipment, as in the studies carried out by Pellinen [28]. The present investigation revealed that in conditions of low rigidity of the specimen, a situation that demands the application of low-intensity loads, the apparent noises are derived from natural physical processes. It was also observed that the natural vibration of the specimen occurs with increasing temperature. Compared to a temperature of $25{ }^{\circ} \mathrm{C}$, the stiffness modulus of the asphalt composition when subjected to $55{ }^{\circ} \mathrm{C}$ resulted in higher values in the order of $10 \%$ of the initial value. Specific to the frequency of application of load pulses of $10 \mathrm{~Hz}$, the stiffness modulus decreased from 1953.4 $\mathrm{MPa}\left(25^{\circ} \mathrm{C}\right)$ to $202.0 \mathrm{MPa}$ at $55^{\circ} \mathrm{C}$ (Table II). In addition to this temperature influence, the natural vibration of the specimen can be significant in any circumstance that implies a substantial decrease in the stiffness of the sample. Such a situation commonly occurs in fatigue tests, in which there is a significant reduction in the material's resistance when approaching rupture. It is interesting to note that the thickness effect is also important in this process [29-32]. Generally, these variations are interpreted as noise, like the data presented by Rowe et al. [33], in a four-point bending test; they used polynomial smoothing to improve the results. It is noteworthy that these results could be improved through the parameters derived from the natural vibration of the specimen, which would maintain the physical relevance of the information, sometimes lost when applying generic filters.

Table II - Average dynamic stiffness modulus (MPa) as a function of frequency and test temperature.

\begin{tabular}{ccccc}
\hline $\begin{array}{c}\text { Temperature } \\
\left({ }^{\circ} \mathrm{C}\right)\end{array}$ & 1 & 3 & 10 & 20 \\
\hline 25 & 1302.0 & 1608.0 & 1953.4 & 1998.2 \\
30 & 1048.6 & 1312.6 & 1649.8 & 1776.6 \\
35 & 712.6 & 940.4 & 1211.6 & 1268.2 \\
40 & 399.6 & 555.4 & 751.8 & 763.4 \\
45 & 235.4 & 331.4 & 457.4 & 534.0 \\
50 & 173.6 & 241.8 & 328.6 & 384.6 \\
55 & 107.0 & 150.2 & 202.0 & 351.6 \\
\hline
\end{tabular}


Beam vibrationanalysis: using the beam natural frequency equation (Eq. D), the geometric data of the specimens, and the dynamic modulus obtained from the tests, the theoretical frequency of the beam's natural vibration was calculated for each loading condition, which resulted in the data in Table III [19]. With regard to the test results, as the temperature increased, oscillations around the applied sine waveform

Table III - Beam natural vibration frequency $(\mathrm{Hz})$ for each loading situation and applied temperature $(\mathrm{n}=1)$.

\begin{tabular}{ccccc}
\hline $\begin{array}{c}\text { Temperature } \\
\left({ }^{\circ} \mathrm{C}\right)\end{array}$ & \multicolumn{4}{c}{ Frequency of application of load $(\mathrm{Hz})$} \\
\hline 25 & 1 & 3 & 10 & 20 \\
30 & 151.28 & 169.13 & 187.37 & 189.74 \\
35 & 109.10 & 126.28 & 144.42 & 144.95 \\
40 & 79.55 & 94.31 & 110.32 & 104.99 \\
45 & 59.96 & 71.02 & 82.81 & 71.68 \\
50 & 51.37 & 60.06 & 68.05 & 47.30 \\
55 & 40.13 & 46.40 & 49.78 & 26.08 \\
\hline
\end{tabular}
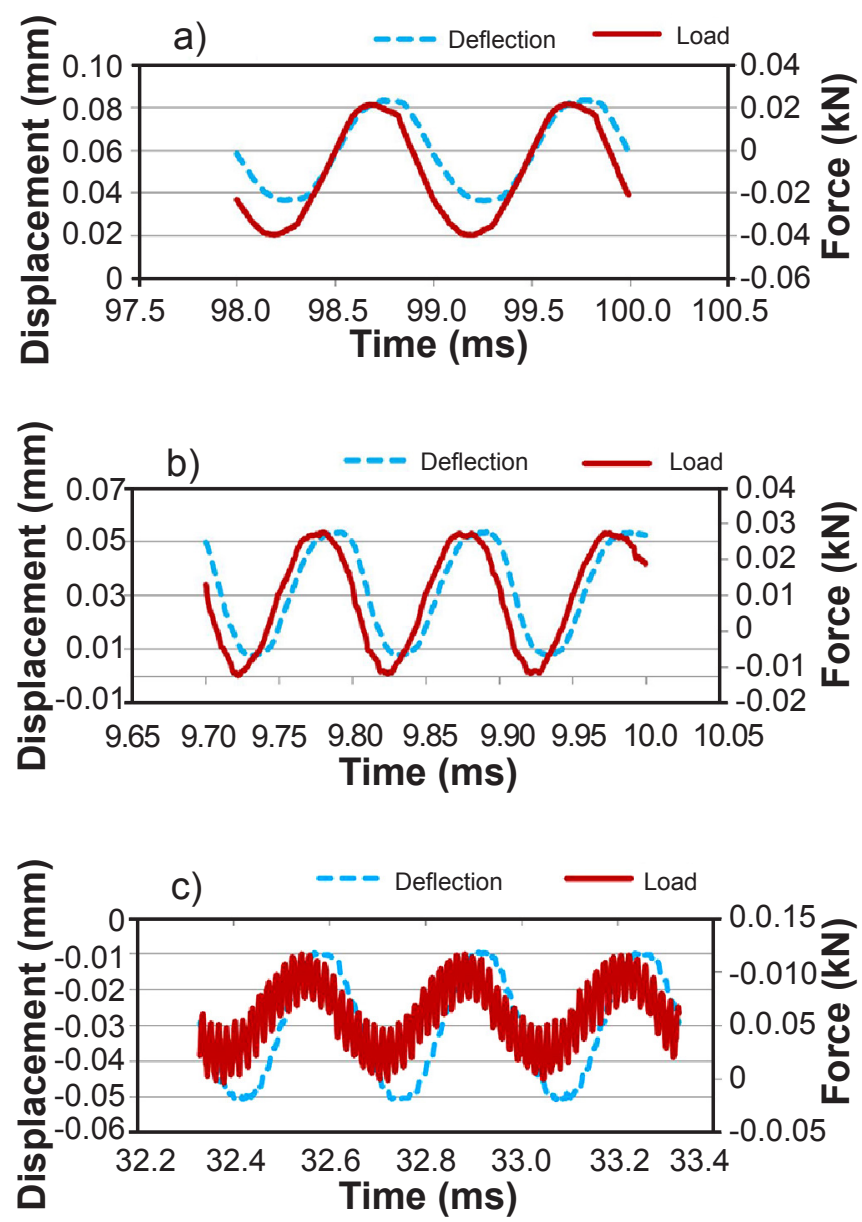

Figure 4: Charts generated for specimens subjected to tests at: a) $25^{\circ} \mathrm{C}$ and pulses of $1 \mathrm{~Hz}$; b) $40{ }^{\circ} \mathrm{C}$ and pulses of $10 \mathrm{~Hz}$; and c) $55^{\circ} \mathrm{C}$ and pulses of $3 \mathrm{~Hz}$. load were observed, which, in a superficial analysis, could be associated with errors or noise in the equipment. The chart in Fig. 4a outlines the load pulses and the corresponding deflection used to calculate the dynamic stiffness modulus. The lag between the pulses, resulting in the phase angle $(\phi)$, can also be seen. Up to $40{ }^{\circ} \mathrm{C}$ and a frequency of $10 \mathrm{~Hz}$, the load pulses and the displacement seemed to be in good compliance, as shown in Fig. 4b. For higher temperatures, although the deflections were recorded accurately, variations in the load pulses were observed, as can be seen in Fig. 4c. Nevertheless, the load pulse conformation was clearly seen, and the data could be statistically analyzed to determine a sinusoidal function that represented the data set.

The oscillations recorded in Fig. 5 occurred due to the beam's natural vibration, as shown below. By analogy, it was noted that the results obtained represent the combination of different waves. Therefore, the increase in temperature was equivalent to the reduction in force amplitude, as a lower load intensity for the same displacement was required, which increased the influence of the natural vibration in the result. For better visualization of the results, two sections were selected for enlargement, which are delimited in Fig. 5 by dashed rectangles: one for $50^{\circ} \mathrm{C}$ and another for $55^{\circ} \mathrm{C}$. In these chart segments, the vibration peaks were identified, the period measured, and the corresponding frequency was calculated. In order to make measurements and calculations feasible, four vibration peaks were delimited, making it possible to determine the start and end intervals of each set (Fig. 6). The calculations performed from the graphic records resulted in an average period of $0.0153 \mathrm{~s}$ and natural frequency $\mathrm{f}_{\mathrm{n}}$ of $65.35 \mathrm{~Hz}$ for the beam at $50^{\circ} \mathrm{C}$, and a period

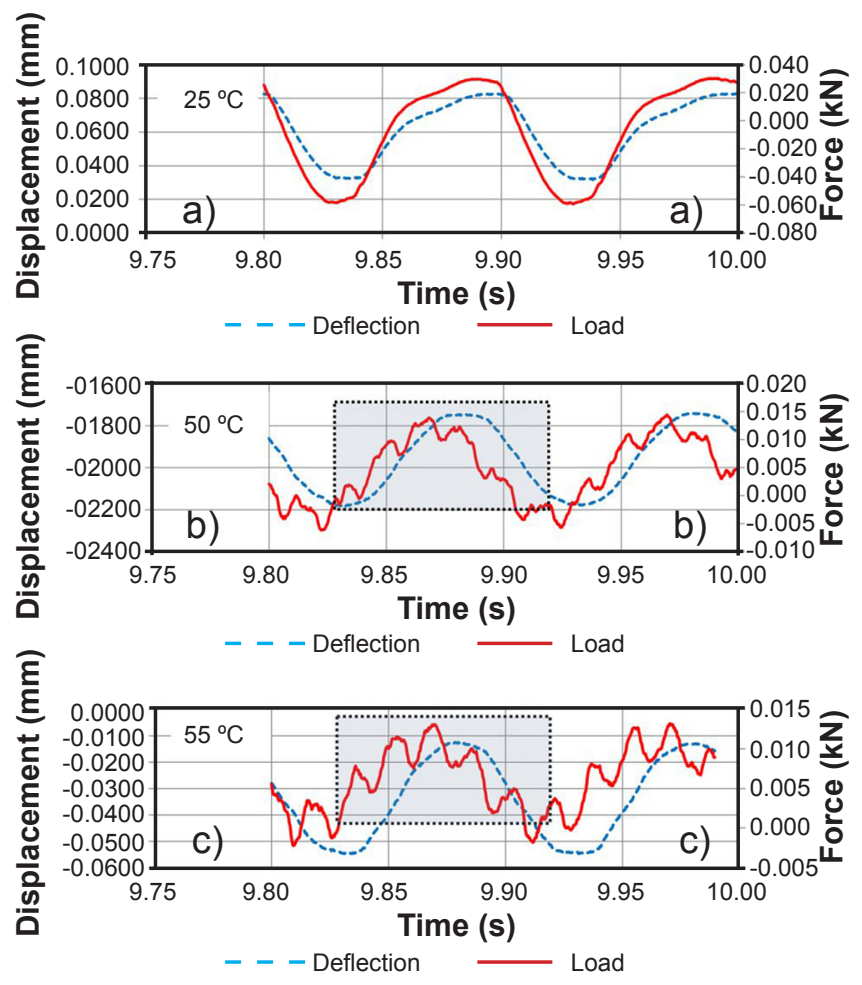

Figure 5: Test results for $10 \mathrm{~Hz}$ frequency and different temperatures. 

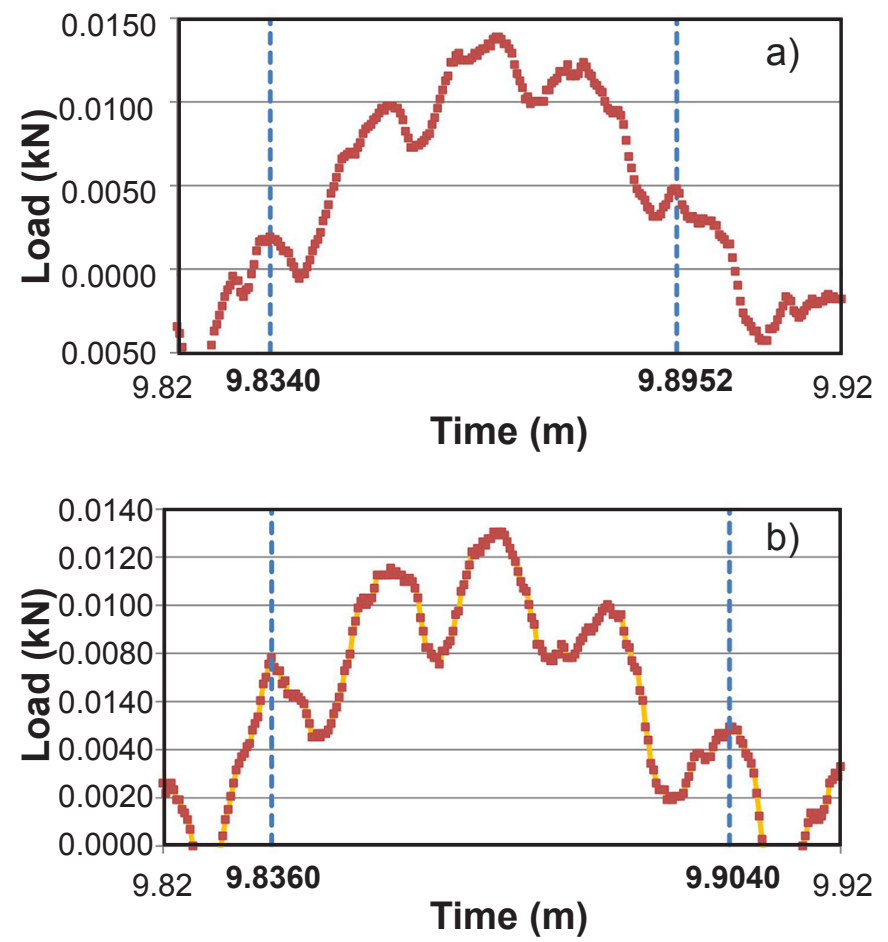

Figure 6: Enlargements of the results shown in: a) Fig. 5b; and b) Fig. 5c.

Table IV - Natural vibration frequencies (measured and calculated).

\begin{tabular}{ccc}
\hline Temperature & $\mathrm{f}_{\mathrm{n}}$ theoretical & $\mathrm{f}_{\mathrm{n}}$ measured \\
\hline $50{ }^{\circ} \mathrm{C}$ & 68.05 & 65.3 \\
$50{ }^{\circ} \mathrm{C}$ & 49.78 & 58.8 \\
& & \\
\hline
\end{tabular}

of $0.0169 \mathrm{~s}$ and frequency of $58.82 \mathrm{~Hz}$ for the same beam at $55{ }^{\circ} \mathrm{C}$. The reduction in frequency with the increase in temperature accompanied the reduction in the elastic modulus, a situation consistent with the equation of the biarticulated beam's natural frequency (Eq. A). At the same time, the frequencies calculated for the peaks identified in the charts of Fig. 6 were close to theoretical natural frequencies (Table IV), which indicated that such oscillations were, in fact, due to the natural vibration of the beam.

\section{CONCLUSIONS}

When performing four-point bending tests on asphalt composites under frequency and temperature conditions that result in a low-load intensity, which is the case of simulations at high temperatures, the results achieved did not show the expected sharpness. As demonstrated in this research, under conditions that lead to low-load intensity, the beam's natural vibration significantly influences the recording of results. Therefore, the lack of sharpness was not due to equipment failures or noise, nor due to the procedure. In this study, the apparent error consisted of interference from the beam's natural vibration, which was not an error but a well-understood physical phenomenon. In situations where it is relevant, knowledge regarding the natural vibration of materials can be used to create a filter and eliminate the apparent noise of the results in order to improve the understanding of the main phenomenon being investigated, which in this case was the stiffness modulus of asphalt composites. Based on the aforementioned, it is concluded that in mechanical analyses of materials that imply high precision of deformation readings and small load intensities, eventual noises in the results may be due to the natural vibration of the specimen, as demonstrated in this research. From this understanding, results can be better adjusted and interpreted.

\section{REFERENCES}

[1] Y.R. Kim, Modeling of asphalt concrete, ASCE Press, New York (2009).

[2] M. Losa, P. Leandri, R. Bacci, Transp. Res. Rec. 2051 (2008) 23.

[3] H.L. Lehmann, V. Adam, Highw. Res. Board Proc. 38 (1959) 398.

[4] V. Aams, S.C. Shah, Transp. Res. Rec. 523 (2008) 88.

[5] R.B. Mallick, F.P. Hooper, S. O’Brien, M. Kashi, Transp. Res. Rec. 1891 (2004) 1.

[6] F.M. Canestrari, G. Bocci, G. Ferroti, P. Pasquini, in Proc. Inter. Conf. Adv. Charact. Pavem. Soil Eng. Mater., Greece (2007) 1643.

[7] T. Takahashi, M.N. Partl, Road Mater. Pavement Des. 2 (2001) 283.

[8] A.C.L. da Silva, C.A. Frota, Cerâmica 59, 352 (2013) 508.

[9] C.L. Silva, C.A. Frota, H.O. Frota, Open J. Civil Eng. 5 (2015) 281.

[10] A.C.L. Silva, C.A. Frota, H.O. Frota, Rev. Matér. 20, 2 (2015) 436.

[11] A.C.L. da Silva, C.A. da Frota, Cerâmica 62, 364 (2016) 392.

[12] J.R. Spinola, A.C.L. Silva, A.G. Pereira, C.A. Frota, Am. Sci. Res. J. Eng. Technol. Sci. 61 (2019) 119.

[13] R.L. Lytton, Transp. Res. Rec. 1723, 1 (2000) 5.

[14] M.H. King, "Determination of dynamic moduli in uniaxial compression for North Carolina hot mix asphalt concrete", M.Sc. Thesis, North Carolina State Un., Raleigh (2004).

[15] T. Pellinen, B. Crockford, in Proc. $6^{\text {th }}$ Int. RILEM Symp., Zurich (2003) 307.

[16] M. Rajesh, J. Pitchaimani, N. Rajini, Procedia Eng. 144 (2016) 1055.

[17] J. Wang, H. Ruan, X. Wang, J. Wan, J. Non. Cryst. Solids 500 (2018) 181.

[18] S. Waddar, J. Pitchaimani, M. Doddamani, E. Barbero, Compos. B Eng. 175 (2019) 107133.

[19] A.C.L. Silva, “Comportamento mecânico de compósitos asfálticos com argila calcinada sob flexão a quatro pontos", M.Sc. Thesis, Fed. Un. Amazonas, Manaus (2014).

[20] J.C. Pais, L. Fontes, P.A.A. Pereira, M.J.C. Minhoto, 
D.S.N.V.A. Kumar, B.T.A. Silva, in Proc. $2^{\text {nd }}$ Workshop Four-point Bending Beam, Guimaraes (2009).

[21] J.C. Pais, J. Harvey (Eds.), Four point bending, CRC Press (2012).

[22] A.C. Pronk, "Theory of the four point dynamic bending test, part I: general theory", Report P-DWW-96-008, Delft Un. Technol., Delft (1996).

[23] M. Huurman, A.C. Pronk, in Proc. $7^{\text {th }}$ Int. RILEM Symp. Adv. Test. Charact. Bitum. Mater., Rhodes (2009).

[24] A.C. Pronk, In Proc. $3^{\text {rd }}$ Workshop Four-point Bending, USA (2011)

[25] L. Fontes, G. Trichês, J. Pais, P. Pereira, in Proc. $2^{\text {nd }}$ Workshop Four-point Bending Beam, Guimaraes (2009).

[26] K.F. Graff, Wave motion in elastic solids, Courier Dover Publ. (1975).
[27] M. Huurman, A.C. Pronk, in Proc. $3^{\text {rd }}$ Conf. Four-point Bending, USA (2012).

[28] T.K. Pellinen, in "Modeling of asphalt concrete", Y.R. Kim (Ed.), McGraw-Hill Constr. (2009).

[29] F. Berto, P. Lazzarin, A. Kotousov, Mech. Mater. 43, 6 (2011) 332 .

[30] F. Berto, P. Lazzarin, C.H. Wang, Int. J. Fract. 127, 3 (2004) 265.

[31] F.J. Gómez, M. Elices, F. Berto, P. Lazzarin, Int. J. Fract. 145, 1 (2007) 29.

[32] F. Berto, A. Campagnolo, M. Elices, P. Lazzarin, Mater. Des. 49 (2013) 826.

[33] G.M. Rowe, P. Blankenship, T. Bennert, in Proc. $3^{\text {rd }}$ Conf. Four-point Bending, USA (2012) 113.

(Rec. 14/01/2021, Rev. 26/03/2021, Ac. 05/04/2021) 